\title{
Greta Billing
}

\section{FRANSK KULTUR-OG REGIONAL- POLITIKK i 1960 og 70 årene}

\section{En impresjonistisk studie}

I dette notat pretenderer jeg ikke å gi en analyse av fransk kultur- og regionalpolitikk, men å formidle endel av mine inntrykk fra en studiereise $\mathrm{i}$ Paris-regionen sommeren 1974.

Unesco har erklært året 1975 for verdens kultur år. Denne beslutningen er resultatet av internasjonale konferanser i Unesco regi, den første på ministerplan ble holdt sommeren 1970 i Venezia. Konferansen tok opp de institusjonelle, administrative og finansielle aspekter ved kulturpolitikken i de respektive land. Konferansen viste at regjeringene hadde besluttet å møte tidens nye krav og fra nå av akseptere ansvaret for kulturutviklingen som av integrert del av den generelle samfunnsutvikling. (René Maheu, generaldirektar i Unesco). Konferansen konkluderer med behovet for å opp-prioritere det kulturpolitiske arbeide, og nødvendigheten av økt statlig engasjement på kulturområdet.

Augustin Girard fikk i oppdrag av Unesco å summere og videreutvikle konferansens synspunkter, og jeg kan henvise interesserte til boka hans: "Cultural development: experience and policies«.

Frankrike har spilt en aktiv rolle på Unesco-konferansene, og fransk kulturpolitikk har tjent som modell for sosialdemokratenes forslag 1972 til »Ny kulturpolitik « i Sverige, og regjeringene Brattelis og Korvalds Kulturmeldinger i Norge 1973-74.

l Frankrike ble kulturområdet skilt ut som eget ministerium i 1959, med André Malraux som innflytelsesrik minister under de Gaulle.

Diskusjonen om statens engasjement i kulturpolitkken ble intensivert utover i 60-årene. Det blev produsert "mange utredninger og vakre taler. Frankrike sto foran en »Revolution culturelle«, en »Revolution Pacific» (commision du $\mathrm{V}^{e}$ plan) og Frankrike ville formidle til andre land en $» \mathrm{Ci}$ vilisation de la culture«. Malraux slo fast i deputérkammeret oktober 1966 at wethvert barn skal ha like stor rett til malerier, teatre, kino osv. som til alfabetet! «2 Menneskeretten til skultur « skulle være en ny etappe i menneskerettighetserklæringen, et nytt ledd i de borgelige rettighetene. ${ }^{2}$ (s. 11)

Malraux ble eksponenten for denne franske kulturpolitikken, med en nesten religiøs nasjonalisme, eller det jeg vil kalle en kulturell imperialisme.

Malraux erklærte videre i talen i deputerkammeret at

„Pour le prix de vingt-cinq kilometres d'autoroute... la France quia ete le premier pays culturel du monde en son temps... peut, dans les dix années qui 
viendront, redevenir le premier pays culturel du monde en son temps... (Til en pris av $25 \mathrm{~km}$ autobane kan Frankrike, som i sin tid var det fremste kulturland, i det kommende tiăr gjenerobre posisjonen:)2 (s.9)

Malraux ville sende fransk kultur utover (i) verden, dvs. han sendte $»$ Mona Lisa« til U.S.A., "Venus fra Milo« til Japan, og dro selv på representasjonsreiser!

"Frankrike skal få en misjon som den fremste kulturnasjon, som stiller historiens ypperste kunstverk til disposisjon for alle « Fransk kultur skulle gi verden et tredje alternativ, "Une voie francaise ala culture « et alternativ til USA's liberalisme og Sovjets rigide styring.

"... Frankrike eksisterer ikke bare for seg selv, men for hele menneskeheten « (Malraux i Amiens 1966).

Innenfor den nasjonale ramme var Malraux's visjon at den kulturelle aksjon skulle få like stor betydning i franskmenns liv som innføringen av den obligatoriske folkeskolen. Malraux's kongstanke var å bygge kulturhus utover i Frankrike, hvor alle franskmenn kunne få tilgang til det ypperste i fransk kultur, alt det som tidligere var forbeholdt pariserne. Tanken om en kulturelle desentralisering ble neste ledd.

I 1971 var det 85 kultur- og fritidshus i Frankrike. Kulturhusene, »det 20. århundres katedraler«(Malraux), fikk litt forskjellig utforming: fellestrekket var vekten på săkalt »finkulturelle« aktiviteter som teatersal, konsertsal, mediatek og studierom.

De nye kulturhusene er plassert i forskejllige sentra rundt om i Frankrike, noen i gamle ærverdige byer, mens andre er bygd i de administrative sentra $\mathrm{i}$ "les nouvelles villes «- de nye byene. Og det er den siste typen som vi skal se litt nærmere på, fordi den sier oss mest om hvordan kulturpolitikken ble brukt som et redskap i den statlige samfunnsplanlegging slik mălsettingen var.

Slagordet om regional- og kulturell desentralisering, hva innebar så det?

\section{Den Vog VI Plan}

Studerer vi da 5. og 6. plan for fransk samfunnsutvikling for periodene 1966-70 og 1971-75, finner vi at det pekes på en sammenheng mellom rask urbanisering, miljøproblemer og sosial uro. "Menneskene er ikke sosialt integrert, de mangler kultur«. Planene gir retningslinjer for å styre urbaniseringsprosesser. Mest detaljert er planen for Paris-regionen, og vi skal se litt nærmere på den, slik den er fremstilt $\mathrm{i}$ "S Schema directur d'aménagement et d'urbanisme de la region de Paris« (L'institut d'amenagment et d'urbanisme de la region parisienne 1965 ).

Paris hadde i $1973 \mathrm{ca} .9$ mill innb. og skal etter planen ha 14 mill innen år 2000. Samtidig utvikles det 5 nye byer $i$ en avstand av 5-18 mil fra Paris, med Seinen som akse. Disse 5 by-områdene hadde i 1962 da planen ble utarbeidet. ca. $110.000 \mathrm{innb}$. og vil i år 2000 ha 4,5 mill innb. Hele Paris-regionen vil altså ha ca. 18,5 mill innb. år 2000. Hele Frankrike antas da å ha 75 mill innb. (mot 
idag ca 50 mill) Det betyr at idag bor ca $20 \%$ av Frankrikes innbyggere i Parisregionen, og år $2000 \mathrm{ca} 25 \%$.

Lokaliseringen av de nye-byene begrunnes i planen: "De nye bysentra som er aksen $\mathrm{i}$ den planlagte urbanisering og transportutvikling, ligger sentralt geografisk, økonomisk og kulturelt, i Paris-området, i hjertet av Frankrike og Europa«! Mer beskjedent nevnes industriens krav til havn og vann som forutsetning for etablering i de nye by-områdene.

Planen legger stor vekt på uviklingen av kultur og fritidstilbud. I planen for hver enkelt ny-by finner vi beskrivelse av kulturhus, fritidshus og mgrøntområder « i tillegg til den vanlige omgivelsen av bolig- og ind ustriområder. På budsjettet for familie-departementet $ø$ kte posten »fritid « $180 \%$ fra 1950 til 60 . I 1960 var posten på 15 milliarder fr., og i 1970 på 30 milliarder fr.

Disse tallene virker svært lovende og optimistiske. Mer opplysende for oss er det kanskje å se nærmere på hvordan planen for en av de fem nye-byene realiseres i praksis, om utopien om en by for whomo ludens « blir virkelighet.

\section{CERG Y-PONTOISE - »une nouvelle ville»}

En »ny-by«, »une nouvelle ville « eller »a newtown« hva er så det? Concepten »ny-by« er utviklet i England i dette hundreåret. Siktemålet var å tilpasse den engelske have-by-ideologien til urbaniseringsprosessen. The new town skulle kunne tilby både arbeid, bolig og rekreasjonsmuligheter. Man prøvde å bevare noen av lokalsamf unnets kvaliteter, med vekt på lave hus, god nabokontakt og kort reise til arbeid, skole eller servicesentra.

ldéen om »les nouvelles villes « er skåret over den engelske lesten. Beboerne skal ha rett til arbeid, bolig og kultur.

"Utviklingen av de nye byene er en av de viktigste hendingene $\mathrm{i}$ annen halvdel av det 20 . århundre... de nye byene vil i 1980 reflektere vår post industrielle sivilisasjon. Problemene som har hopet seg opp i industribyer gjennom 150 år pga. manglende planlegging, kan nå utvikle en ny sivilisasjon «.

Og den kulturelle hovedoppgave $\mathrm{i}$ de nye byene er:

"... to enable the future inhabitants to discover what constitutes a town, a town to be built, to be made beautiful to look at, affording a satisfactory human and practical environment, to help them find out, together with the experts, what a new town needs to make it a place where life is full, where the children are happy and where poetry is close at hand « ${ }^{1}$ (s. 82-83) Hvordan står det så til med poesien i Cergy-Pontoise?

\section{CERGY-PONTOISE - et eksempel}

Cergy-Pontoise er slått sammen av to tettsteder Cergy og Pontoise til en ny-by, og omfatter et areal på 10.850 ha. Byområdet ligger ca. 2,5 mil nord-vest for 
Paris, og jeg besøkte den i august i år. Mine inntrykk baserer seg vesentlig på wdeltakende observasjon « og samtaler med informasjonssjefen for planleggingssentret og direktøren for kultursenteret. Disse to institusjonene arbeidet helt uavhengig av hverandre, og sorterte under hvert sitt departement. CergyPontoise hadde i 1970 ca. 74.000 innb., og skal utvikles til 330.000 innb. Byggingen av la nouvelle ville Cergy-Pontoise tok til i 1970.

Bulldozere og gravemaskiner var mitt første møte med byområdet, og det var vondt for et norsk hjerte å kjøre på nylagte veier gjennom høstgule kornåkre! Overraskende store deler av byen var allerede utbygd, deriblant det administrative- og kulturelle sentrum.

Hvem var så innbyggerne i Cergy-Pontoise, og hvordan var deres bolig-, arbeids- og fritidsniljø?

De som tidligere hadde bodd i området hadde vært imot planen om en "nyby«. De ble ikke rådspurt, og heller ikke tat med i planleggingsprosessen. De nye innflytterne ble rinueligvis heller ikke spurt til råds, for ingen visste dengang hvem de var. I dag vet vi at det vesentlig er fremmedarbeidere, franskmen fra distriktene og arbeidere fra Paris som nå bo i Cergy-Pontoise. Gjennomsnittsalderen var lav, med overvekt av småbarns-familier.

Det var utviklet 27.000 nye arbeidsplasser i området vesentlig i industri og handel. Og det var uten tvil det bedre bolig- og arbeidstilbudet enn Paris kunne tilby som hadde motivert innflytterne.

De fleste som bodde i Cergy-Pontoise hadde arbeid der også, altså kort reisetid til jobben, og dette punktet så ut til å være det mest vellykkede etter planen.

I boligområdene var det lagt stor vekt på den arkitektoniske utforming. Husene var malt i sterke farger og gjerne dekorert med bilder av mosaikk. Noen boligblokker var på 14 etasjer, de fleste på 4, og en del eneboliger. Husene lå tildels gruppert som geometriske figurer. Biltrafikken var regulert utenom boligfeltene.

Men hvordan var det så å leve i La ville nouvelle Cergy-Pontoise?

Hadde politikerne og planleggerne lykkes i en bedre forening av byutvikling og »trivsel « slik visjonen var? Fungerte kulturtilbudene som et inntak til en ny livskvalitet? En liten indikasjon får vi ved å se på bruken av kulturtilbudene.

\section{»Une ville nouvelle« - » La vie nouvelle«?}

I en reklamebrosjyre for "La ville nouvelle Cergy-Pontoise « leser vi hva byen tilbyr av kultur-og fritidsliv: Sportsstadion, svømmehall, grøntonråder, skog, en innsjø, skoler, - i kulturhuset et mediatek og to teater, et pedagogisk senter og et museum for moderne kunst, samt et hotell med konferanserom. CergyPontoise håper $\mathrm{i}$ sin tid å få en fast gruppe skuespillere knyttet til teatret.

Altså et ganske "tradisjonelt « tilbud. Den »kulturelle revolusjon« virket fjern for brosjyren, og rykket heller ikke nærmere i virkeligheten. 
Kultursenteret lå i Pontoise, med kulturhuset som midtpunkt. Direktør Daniel Girard på pekte at det var satt mye inn påa få dette huset fort ferdig, slik at man kunne vise til »konkrete resultater« av bevilgningene på kultur- og fritids-budsjettet.

Ble så kultur-tilbudene brukt? Direktør Daniel Girard opplyste at besøksfrekvensen til kulturhuset var lav. Besøket viste stor overvekt av borgerskap og intellektuelle, mens arbeiderne uteble. (Girard fortalte at man arbeidet med en ny typ kulturhus som skulle prøveå imøtekomme arbeidernes kulturelle behov, uten at disse ennå var nærmere spesifisert!)

Kulturhuset hadde arrangert flere utstillinger av kjente kunstnere, og hatt teater- og konsert-besøk fra Paris. Endel av planen for kulturhusets virksomhet var at profesjonelle kunstnere og a matører skulle arbeide sammen for gjensidig inspirasjon. Cergy-Pontoise hadde også importertt kunstnere fra Paris som fritidsledere og instruktører, men med liten respons hos befolkningen.

Kultursenterets kontaktflate med befolkningen sviktet altså, og det til tross for de mange animatørenes abeid for å gjøre tilbudene kjent blant beboerne.

"Animatør« er en relativt ny profesjon $i$ fransk og internasjonal sammenheng. Det foreligger planer for en tilsvarende utdanning i Skandinavia, så det kan være nyttig for oss å se nærmere på animatør-virksomheten.

\section{Animatorer og animasjon}

"Animatører utøver en rekke funksjoner som har det til felles at de skal forbedre kvaliteten i det sosiale liv $\star^{4}$ (s. 3)

Betegnelsene sanimateur \& og »animation« - fikk nytt innhold i Frankrike i tiden 1955-60. l begynnelsen var begrepet "animasjon « knyttet til den sosiokulturelle sektor, og særlig til ungdoms-og fritidsarbeid. Begrepet utvides så til å omfatte andre grupper og formål, og virksomheten făr en klar politiske funksjon.

Animasjonen ble utvidet fra å være knyttet til territoriale områder (byer, distrikter, landsbyer, boligområder) og til å bli en altomfattende virksomhet innen sosiale grupper av alle slag og på alle områder i samfunnet.

1 byområder settes animasjonstiltakene inn i overgangsfasen fra rasjonalisering til økonomisk utvikling for å kunne gi alle innbyggere aktivitetstilbud... med det mål å kontrollere den samfunnsmessige endringsprosess i området. ${ }^{4}$ (s. 3)

Hva kreves det så for å bli en en animatør? Ikke lite!

wHan må være en sterk personlighet. Han må kunne omgås alle slags mennesker og være vant med team-arbeid, være ansvarsbevisst og ha god helse. Dessuten må han ha god teknisk, kulturell og økonomisk kunnskap. ${ }^{4}$ (s. 4)

Animatørprofesjonen har 5 grader, fra typen fritidsklubb-arbeider til en administrativ stilling innen kulturplanleggingsbyråkratiet. Animatørene 
kvalifiserer seg gjennom praktisk arbeid og gjennom 3 eksamener, B.A.S.E. (Diplom i sosio-edukativ animasjon), C.A.P.A.S.E. (Sertifikat i å organisere sosio-edukative aktiviteter), D.U.T. (Universitetsdiplom i teknologi)

Antallet profesjonelle a matører var $6.500 \mathrm{i} 1971$. VI ${ }^{\mathrm{e}}$ Plan des loisirs foreslår at antallet økes til 25.000 innen 1976.

Animatørprofesjonen skal ha en apolitisk funksjon iflge målsettingen, men personlig må hun/han være mnøytral« $\mathrm{i}$ sin virksomhet:

"Animatøren er på samme tid ansvarlig både overfor sin arbeidsgruppe og

for de lokale myndigheter som er hans arbeidsgiver. Han må være nøytral og respektere alle meninger ${ }^{4}{ }^{4}$ (s.4)

I Cergy-Pontoise var det ansatt animatører på flere nivåer, i bomiljøet, - for å gi praktiske informasjoner og provosere fram nabok ontakt og kollektivt liv. I kulturhuset som ledere og instruktører på de ulike mediaområdene. (Direktør D. Girard hadde også animatørutdanning). Og noen arbeidet som tradisjonelle sosialarbeidere og fritidsledere.

I praksis viste det seg at sosialarbeiderne hadde mest å gjøre med å hjelpe folk til rette $\mathrm{i}$ en ny boligsituasjon. De andre animatørgruppene hadde vanskelig for å komme i kontakt med befolkningen.

Det ser altså ut til at det sosiale livet i Cergy-Pontoise ikke skiller seg særlig fra livet andre steder i Frankrike. "La vie nouvelle« ble ikke skapt samtidig med »la ville nouvelle«. Den kulturelle revolusjon lar vente på seg. Folk ser fjernsyn framfor teater også i Cergy-Pontoise. Og liksom i andre tillflyttingsområder hadde beboerne store sosiale tilpassningsproblemer, særlig fordi innflytterne hadde svært ulik sosial og kulturell bakgrunn, blant annet et stort innslag av fremmedarbeidere. Men Cergy-Pontoise hadde gitt dem et bedre bolig og arbeidstilbud enn Paris, som var eneste alternativ.

Cergy-Pontoise var ett eksempel, men det ser ut til at erfaringene fra de 4 andre mye-byene $\mathrm{i}$ Paris-regionen er tilsvarende.

I desember 1973 ble det holdt et seminar i Elancourt for å vurdere erfaringer fra de nye byenes utvikling, med spesiell vekt på animasjonsaspektet.

Kritikken er hard:

"Animasjonstiltakene er en estetisk maske for å dekke over det faktiske forløp, som er en tilpassning av mennesket til produksjonens behov« (s. 5)

\section{OPPSUMMERING:}

Drivkraften i den franske regional- og kulturpolitikk viser seg ikke å være menneskelige behov for en bedre livsstandard, men kapitalens behov for reorganisering og omfordeling av arbeidskraften. Kulturprofeten Malraux sendte så animatører ut i smeltediglene for å bygge kulturhus.

Den statlige samfunnsplanlegging fungerer på kapitalens premisser, og kulturpolitikken er et viktig virkemiddel i kampen om det ideologiske herredømme. Kulturplanleggingen er statens forsøk på å få økt styring og kontroll med lokalsamfunnets verden. 
Folk flytter fra omland og utland inn til Paris, og derfra ut til de nye byer. Fransk urbaniserings- og desentraliseringspolitikk betyr en ytterligere styrking av Paris som metropol med 5 nye satelitt-byer.

Den såkalte kulturelle desentraliseringspolitikk innebar et forsøk på kulturell verdioverføring av en parisdominert borgerlig kultur til arbeiderklassen via »de kulturelle overislingsanlegg«. De nye institusjonene er et produkt av borgerskapets klasseinteresser, og ga staten større mulighet til administrativ styring av lokalsamfunnet, med animatørene som de stedlige representanter.

Med denne nye giv'en i kulturpolitikken har altså mislykkes på to måter, animasjonen har ikke bidratt til à skape en nv livsform og en ny livskvalitet i de nye-byene, og den har heller ikke maktet à fungere ideologisk som en sosial tilpasningsmekanisme til den kapitalistiske utvikling.

Motsetningene kommer til uttrykk på flere plan:

Motsetninger innen byråkratiet mellom statlige og kommunale instanser. Tilbakegangen i statlige bevilgninger til den sosiale-og kulturelle sektor, staten prøver å overføre større del av det finansielle ansvar til kommunene. De reduserte bevilgninger medfører at det prosjekterte sosiokulturelle utstyr bare delvis innvilges, og da i første rekke prestisjebygg som kulturhus.

Animatørene fungerer på det administrative nivå som konfliktdempere mellom stat og kommune, og i lokalsamfunnet som byråkrat og forhandler av borgerlige kulturgoder. Animatørene er redusert til serviceinformanter, uten innovativ og nyskapende funksjon.

Og kunstnere og arkitekter spiller rollen som dekoratører i urbaniseringsprosessen.

Mai-opprøret 1968 førte til en kritisk analyse av regionalpolitikken og de nye byene. Men statsapparatet er ennå ikke rystet i sine grunnvoller, motsetninger kommer ikke til uttrykk som klassekamp, men holdes nede i en langsom integrasjons- og byråkratiseringsprosess.

\section{Henvisninger:}

1. Augustin Girard: „Cultural development: expericnce and policies «. Unesco Paris 1972, ogsâ på transk. Dansk utgave 1974.

2. Pierre Gaudebert: »Action culturelle: integration et/on subversion«. Casterma 1972.

3. London belongs to us. N.BR. Oslo 1973.

4. "Socio educational careers in Francc«. I.N.E.P. Marly-le-Roi 1971.

5. "Document de travail sur la promotion des activités socio-éducatives. I \& 11\%. Sccretariat d'etat, direction de la jeunesse.

6. "Villes nouvelles: De la preanimation a l'animation« Seminaire de travaildec. 1973. P. Saragoussi etc. Elancourt 1973. 